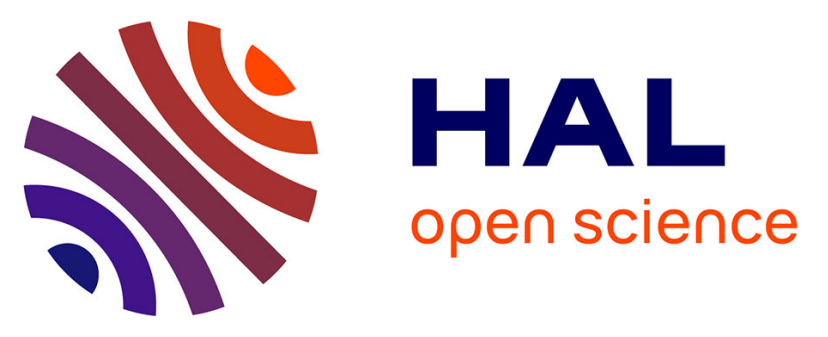

\title{
Contribution of injured posterior ligamentous complex and intervertebral disc on post-traumatic instability at the cervical spine
}

Jean-Marc Mac Thiong, Marie-Hélène Beauséjour, Yvan Petit, Jeremy Hagen, Pierre-Jean Arnoux, Jean-Marc Mac Thiong, Eric Wagnac

\section{To cite this version:}

Jean-Marc Mac Thiong, Marie-Hélène Beauséjour, Yvan Petit, Jeremy Hagen, Pierre-Jean Arnoux, et al.. Contribution of injured posterior ligamentous complex and intervertebral disc on post-traumatic instability at the cervical spine. Computer Methods in Biomechanics and Biomedical Engineering, 2020, 23 (12), pp.832-843. 10.1080/10255842.2020.1767776 . hal-03231404

\section{HAL Id: hal-03231404 \\ https://hal-amu.archives-ouvertes.fr/hal-03231404}

Submitted on 20 May 2021

HAL is a multi-disciplinary open access archive for the deposit and dissemination of scientific research documents, whether they are published or not. The documents may come from teaching and research institutions in France or abroad, or from public or private research centers.
L'archive ouverte pluridisciplinaire HAL, est destinée au dépôt et à la diffusion de documents scientifiques de niveau recherche, publiés ou non, émanant des établissements d'enseignement et de recherche français ou étrangers, des laboratoires publics ou privés.

\section{(ㅇ)(1) $\$$}

Distributed under a Creative Commons Attribution - NonCommercial - NoDerivatives 44.0 


\section{Contribution of Injured Posterior Ligamentous Complex and Intervertebral Disc on Post-Traumatic Instability at the Cervical Spine}

Marie-Hélène Beausejour

Department of Mechanical Engineering, Ecole de technologie superieure, Montreal, Canada

Research Center, Hopital du Sacre-Coeur de Montreal, Montreal, Canada

Laboratoire de biomecanique appliquee, IFSTTAR, LBA UMR T24, Aix-Marseille

Universite, Marseille, France

https://www.linkedin.com/in/marie-hélène-beauséjour-21550a91

Yvan Petit

Department of Mechanical Engineering, Ecole de technologie superieure, Montreal, Canada

Research Center, Hopital du Sacre-Coeur de Montreal, Montreal, Canada

Jeremy Hagen

Department of Mechanical Engineering, Ecole de technologie superieure, Montreal, Canada

Research Center, Hopital du Sacre-Coeur de Montreal, Montreal, Canada

Pierre-Jean Arnoux

Laboratoire de biomecanique appliquee, IFSTTAR, LBA UMR T24, Aix-Marseille Universite, Marseille, France

Jean-Marc Mac Thiong

Research Center, Hopital du Sacre-Coeur de Montreal, Montreal, Canada 


\section{Eric Wagnac}

Department of Mechanical Engineering, Ecole de technologie superieure, Montreal, Canada

Research Center, Hopital du Sacre-Coeur de Montreal, Montreal, Canada

https://www.linkedin.com/in/eric-wagnac-2532bb77

ORCID ID: 0000-0003-3806-7326

Correspondance details :

e-mail corresponding author : eric.wagnac@etsmtl.ca

Phone number : 1 (514) 396-8435

Fax : 1 (514) 396-8530 


\title{
Contribution of Injured Posterior Ligamentous Complex and Intervertebral Disc on Post-Traumatic Instability at the Cervical Spine
}

\author{
Posterior ligamentous complex (PLC) and intervertebral disc (IVD) injuries are \\ common cervical spine flexion-distraction injuries, but the residual stability \\ following their disruption is misknown. The objective of this study was to \\ evaluate the effect of PLC and IVD disruption on post-traumatic cervical spine \\ stability under low flexion moment ( $2 \mathrm{Nm}$ ) using a finite element (FE) model of \\ C2-T1. The PLC was removed first and a progressive disc rupture (one third, two \\ thirds and complete rupture) was modeled to simulate IVD disruption at C2-C3, \\ C4-C5 and C6-C7. At each step, a non-traumatic flexion moment was applied \\ and the change in stability was evaluated. PLC removal had little impact at C2- \\ $\mathrm{C} 3$ but increased local range of motion (ROM) at the injured level by $77.2 \%$ and \\ 190.7\% at C4-C5 and C6-C7 respectively. Complete IVD rupture had the largest \\ impact on $\mathrm{C} 2-\mathrm{C} 3$, increasing $\mathrm{C} 2-\mathrm{C} 3 \mathrm{ROM}$ by $181 \%$ and creating a large antero- \\ posterior displacement of the C2-C3 segment. The FE analysis showed PLC and \\ disc injuries create spinal instability. However, the PLC played a bigger role in \\ the stability of the middle and lower cervical spine while the IVD was more \\ important at the upper cervical spine. Stabilization appears important when \\ managing patients with soft tissue injuries.
}

Keywords: spine; disco-ligamentous structures; post-trauma; injury biomechanics; finite element modeling

\section{Introduction}

The posterior ligamentous complex (PLC), which comprises the ligamentum flavum (LF), interspinous ligament (ISL) and nuchal ligament (NL) (Rasoulinejad et al. 2012), and the intervertebral disc (IVD) (Nadeau et al. 2012) play a critical role in cervical spine stability. Flexion-distraction injuries characterized by PLC and IVD disruption are frequent at the cervical spine and result in serious neurological consequences (Blauth et al. 2007). 
In vitro studies have proposed stability criteria based on the comparison of preand post-trauma flexibility (Goel et al. 1984; White and Panjabi 1990). At the cervical spine, the changes in angular and horizontal displacement prior to failure in flexion and extension was evaluated in vitro by reducing the disco-ligamentous elements sequentially from the anterior or posterior (White et al. 1975). However, specimens of only one functional spinal unit (FSU) were used. The impact of sequential removal of NL, ISL and facet capsules (FC) at C5-C6 on rotation at C4-C5 and C5-C6 was evaluated in all three anatomical planes using C2-T2 segments but only up to $0.3 \mathrm{Nm}$ (Goel et al. 1984). One study tested the impact of sequential disco-ligamentous injuries at C5-C6 inflicted from the anterior on the neutral zone and range of motion (ROM) (Richter et al. 2000). Another study evaluated the effect of discectomy, anterior fixation and the subsequent progressive disruption of the PLC on the intervertebral ROM (Pitzen et al. 2003), but little is known about the contribution of the PLC versus the IVD in flexion-distraction type injuries on spinal stability at the cervical spine.

Finite element (FE) models have been used to evaluate the contribution of different structures under quasi-static (Ng and Teo 2001; Erbulut et al. 2014), low and high dynamic loading conditions (DeWit and Cronin 2012; Mustafy et al. 2016). However, no FE study has investigated spinal instability induced by annulus fibrosus (AF) rupture while it is frequent in flexion-distraction injuries of the cervical spine (Crowell et al. 1993; Taylor and Twomey 1993).

Secondary spinal cord injury can be aggravated by patient management (Engsberg et al. 2013) due to joint instabilities. However, unlike unstable bone fractures and dislocations, the level of prehospital immobilization required to prevent luxation 
and secondary spinal injuries remains unclear (Ala'a et al. 2015). Cervical collars (CC) are commonly used following neck trauma to limit movement during pre-hospital care and transportation. However, their efficiency has been criticized. A study conducted on healthy volunteers showed that different $\mathrm{CC}$ were mostly successful at reducing axial rotation while 19.8 to $40.7 \%$ of flexion is preserved compared to no collar (Kim et al. 2018). Log-roll transfers simulations performed by paramedics on healthy volunteers wearing a $\mathrm{CC}$ showed peak relative head motion of 9.5 to 40.8 degrees (Lebel et al. 2018). Horodyski et al. (2011) measured around 30 degrees of flexion on a cadaver model wearing a CC with a C5-C6 global instability. Excessive flexion is very undesirable following flexion-distraction injuries since it could lead to subluxation at the injured level (Blauth et al. 2007) and cause or aggravate a spinal cord injury. However, the extent of posterior disco-ligamentous injury that should be considered critical and would require proper immobilization is not known.

The main objective of this study was to investigate the relative contribution of the PLC and IVD on the post-traumatic spinal stability of the cervical spine under low flexion moment following a flexion-distraction injury using a C2-T1 FE model.

\section{Materials and methods}

\section{Finite Element Model}

A detailed C2-T1 finite element model presented previously (Taso et al. 2015) was used for this study (Fig. 1a). The initial model included the vertebrae, IVD and cervical spinal ligaments. The $\mathrm{C} 2-\mathrm{C} 7$ cobb angle of the model is 22.7 degrees of lordosis which corresponds to an upright position in comparison to data from healthy volunteers (Gore et al. 1986).Surface models of vertebrae were created from computed tomography scan 
images (contiguous slices of $0.6 \mathrm{~mm}$ ) of a 50th percentile male volunteer. In consequence, the geometry of the model is naturally asymmetrical. The surface models were meshed using 3-nodes shell elements. Cancellous bone of each vertebra was obtained by filling shell elements with 4-nodes solid elements (Wagnac et al. 2012). The average characteristic size of the elements for the vertebra was $0.77 \mathrm{~mm}$. In this quasi-static study, the vertebrae were set as rigid bodies. IVD were created between adjacent vertebral endplates and divided into nucleus pulposus and AF. Tied interfaces, kinematic links, were modeled between the caudal and cranial surface of the IVD and the adjacent vertebral endplates. The nucleus occupies $20 \%$ of disc volume at the cervical segment (Park et al. 2015). Both structures were meshed using 8-nodes solid elements with an average characteristic size of $0.9 \mathrm{~mm}$. First-order Mooney-Rivlin hyper-elastic material laws with non-pathological quasi-static properties (Schmidt et al. 2006) were assigned to these elements (Table 1). Collagen fibers were embedded into the AF using tension-only spring elements organized in concentric lamella with a crosswise pattern at $\pm 35^{\circ}$. Six spinal ligaments were created between each FSU: anterior longitudinal ligament (ALL), posterior longitudinal ligament (PLL), capsular ligament (CL), LF, ISL and NL (Fig. 1b). The ligaments geometry and insertion were based on dissection sessions data (Pintar et al. 1992; Przybylski et al. 1996). They were meshed using 3-nodes (CL only) and 4-nodes shell elements with an average characteristic size of $0.63 \mathrm{~mm}$. The facet joints were considered as frictionless contact interfaces. The model contains 391941 elements and 905223 nodes

In this study, modifications were done to the FE model to improve its flexionextension behavior under quasi-static flexion-extension loadings. In brief, quasi-static material properties were implemented to the IVD components and non-linear stress- 
strain curves were applied to the ligaments. These properties were then calibrated to adjust the intradiscal pressure and the flexion-extension range of motion (ROM) of the model as described below.

The disc was separated into three sections (anterior, posterior and lateral) with collagen fibers force-displacement curves scaled by a specific factor (Table 1) (Schmidt et al. 2006). The nucleus parameters $\mathrm{C}_{10}$ and $\mathrm{C}_{01}$ of the Mooney-Rivlin material law were calibrated by a factor $\mathrm{f}=2$ (Table 1 ) to adjust the intradiscal pressure (IDP) in comparison to in vitro results (Pospiech et al. 1999). [Table 1 near here] The IDP was measured as the average of the pressure, corresponding to the negative one-third of the trace of the stress tensor, of all the nucleus elements.

Stress-strain curves of each ligament were derived from mean force-deflection curves measured experimentally under tensile conditions (Mattucci et al. 2012; Mattucci and Cronin 2015). The ISL force-deflection curves were applied to the adjacent NL since this ligament was not included in the aforementioned studies. The curves were calibrated using the method further described. [Figure 1 near here]

\section{Calibration of the Finite Element Model}

Pure moments of $2 \mathrm{Nm}$ in flexion and extension were applied on $\mathrm{C} 2$, in the sagittal plane defined by the global coordinate system (Fig. 1), while T1 was fixed to reproduce experimental conditions (Wheeldon et al. 2006). The coordinate system and point of origin were defined by the CT-scan reconstruction and corresponds to the standard anatomical planes and axes. Ligaments properties were adjusted by shifting the "toe region" of the tabulated curves until the simulated ROM fitted into the experimental corridors (Nightingale et al. 2002; Wheeldon et al. 2006; Nightingale et al. 2007) as 
previously proposed (Kallemeyn et al. 2010). This adjustment was necessary to take into account the ligaments initial elongation in the model. C2-T1 ROM in flexionextension was finally compared to in vitro data (Wheeldon et al. 2006). The ROM were calculated from the rotation in the sagittal plane of each FSU in the global coordinate system.

\section{Simulation of Posterior Ligamentous Complex and Intervertebral Disc Injury}

PLC injury was modeled by removing the NL, ISL and LF (injury configuration \#1). The disc injury was modeled by splitting the disc postero-anteriorly at the middle of the disc (Fig. 2) and removing the PLL. The injury was modeled progressively as a third of the disc antero-posterior length, two thirds and finally the disc was completely transected (injury configurations \#2 to 4). A frictionless contact interface was added between the disc caudal and cranial parts of the ruptured IVD. The CL was kept intact since its resistance is important in flexion. For distraction injuries without dislocation, the disruption can propagate through the disc space or through the facet joints (Vaccaro et al. 2007). A numerical study also showed no CL rupture prior to segment failure during a flexion loading (DeWit and Cronin 2012). [Figure 2 near here]

For each configuration, a pure moment of $2 \mathrm{Nm}$ was applied on $\mathrm{C} 2$ while $\mathrm{T} 1$ was fixed. Stepwise reduction (injury \#1 to 4) was performed on one spinal level at a time: at $\mathrm{C} 2-\mathrm{C} 3$, then $\mathrm{C} 4-\mathrm{C} 5$ and then $\mathrm{C} 6-\mathrm{C} 7$. This created three different injury sets, each starting with the intact model as baseline. Flexion loading was performed since the posterior elements are mainly solicited in flexion (White and Panjabi 1990) and flexion could lead to dislocation and spinal cord injury. Post-traumatic ROM and the vertebrae centroids position at $2 \mathrm{Nm}$ flexion, in the global coordinate system, were compared to 
the intact model. These results were chosen to evaluate instability and potential spinal canal reduction.

The finite element model was developed on the HyperWorks 2017 software platform (Altair Engineering, Troy MI, USA). The simulations were run on Radioss Solver (Altair Engineering and the analyses performed were non-linear.

\section{Results}

\section{Calibration and Validation}

Following calibration of the ligaments "toe region", the ROM around the coronal axis (flexion and extension) of each FSU was within one standard deviation of the average experimental measurements except for $\mathrm{C} 5-\mathrm{C} 6$ at $2 \mathrm{Nm}$ flexion which was within two standard deviations (Fig. 3). In flexion, C2-T1 ROM was within one standard deviation and only $14 \%$ smaller than experimental average at $2 \mathrm{Nm}$ (Fig. 4). [Figures 3 and 4 near here] In extension, the ROM was within two standard deviations. As one standard deviation only includes $66 \%$ of the experimental values, the simulated motion fitted well inside the experimental corridors. C3-C4 and C5-C6 IDP at flexion of 0.5 Nm were inside the experimental range (Fig. 5). [Figure 5 near here]

\section{Effect of Posterior Ligamentous Complex and Intervertebral Disc Injury}

Changes in the FSU ROM following the injuries are displayed in Fig. 6. PLC rupture increased the ROM at the injured level by $24.3 \%, 77.2 \%$ and $190.7 \%$ at C2-C3, C4-C5 and C6-C7 respectively. Complete disc rupture caused an increase in ROM at the injured level of $181.4 \%, 120.4 \%$ and $284.9 \%$ at C2-C3, C4-C5 and C6-C7 respectively. The changes in ROM at the uninjured levels were under 2 degrees in absolute values for every injury scenario. [Figure 6 near here] 
The vertebrae centroids position in the sagittal plane (Fig. 7) showed no specific rearrangement for injuries at $\mathrm{C} 4-\mathrm{C} 5$ and $\mathrm{C} 6-\mathrm{C} 7$. For PLC disruption at $\mathrm{C} 2-\mathrm{C} 3$, the antero-posterior gap between $\mathrm{C} 2$ and $\mathrm{C} 3$ was $9 \mathrm{~mm}$ greater compared to baseline and 4 $\mathrm{mm}$ greater for complete disc rupture. This is considerable since the antero-posterior diameter of the spinal canal is between 11 and $17 \mathrm{~mm}$ in the model. Also, a facets subluxation was visible for complete disc rupture at C2-C3: C2 inferior facets were translated $3 \mathrm{~mm}$ more anteriorly onto $\mathrm{C} 3$ superior facets at $2 \mathrm{Nm}$ flexion compared to the baseline (Fig. 8). [Figures 7 and 8 near here]

\section{Discussion}

The objective of this study was to evaluate the relative impact of PLC rupture and progressive transversal disc rupture on cervical spine stability in flexion. A FE model (Taso et al. 2015) was adapted by implementing detailed experimental stress-strain curves to represent the ligaments behavior. The ligaments "toe-regions" were calibrated to adjust the ROM of each FSU with experimental corridors. Nucleus properties were also calibrated to adjust the IDP in reference to in vitro data.

The PLC and disc injuries modeled increased the local ROM at the injured FSU but had little impact on the other levels. Goel et al. (1984), observed an average increase of 2 degrees on the C4-C5 flexion ROM for a resection of the NL and LF at C5-C6 which is higher but similar to our results.

PLC disruption at C4-C5 and C6-C7 had an important impact on local ROM at the injured level, but not at C2-C3. Panjabi et al. (1975) reported an increase of $21.2 \%$ at $\mathrm{C} 2-\mathrm{C} 3$ after disruption of the PLC which matches closely the $24.3 \%$ increase 
obtained in our FE analysis. Spine instability created by PLC disruption increased from the cranial to the caudal end of the segment. Another numerical study similarly concluded that ISL removal at C4-C5 creates important instability during flexion (Erbulut et al. 2014) while Goel et al. (1984) showed that removal of LF following reduction of NL and ISL at C5-C6 had a statistically significant impact on local ROM in flexion. Cervical injuries cranial to $\mathrm{C} 4$ are often described as life threatening (Fujimura et al. 1995), but caudal injuries should also receive extra care due to their higher spinal instability in flexion.

Disc rupture increased local ROM at the injured FSU for all levels but had more impact at C2-C3 in comparison to PLC disruption. This could be caused by the proximity of C2-C3 to the moment application point (C2) or by its specific morphology. However, flexion-distraction injuries without bone fracture are not common at C2-C3 (Jubert et al. 2013). A clinical study reported a few cases of "flexion sprain" at C2-C3 in adolescents causing important post-traumatic dynamic instability: antero-posterior translation of 4 to $4.5 \mathrm{~mm}$ and $\mathrm{C} 2-\mathrm{C} 3$ rotation flexion of 13 to 15 degrees measured on dynamic flexion-extension X-Rays (McLoughlin et al. 2014). These results are similar to what we observed at C2-C3 (antero-posterior translations of 4 and $9 \mathrm{~mm}$ and local ROM ranging from 8.6 to 19.4). A non-linear effect on local ROM increase at the injured level was seen from $\mathrm{C} 2-\mathrm{C} 3$ to $\mathrm{C} 4-\mathrm{C} 5$ to $\mathrm{C} 6-\mathrm{C} 7$ for disc disruption. This could be caused by morphological differences (i.e. vertebral shape and facet orientation) between the subaxial and upper cervical spine. Pitzen et al. (2003) produced a discectomy at C5C6 in vitro and observed a ROM increase of $126 \%$ which is close to our results at the injured level for complete disc rupture at C4-C5 (120\%) but lower than the difference at C6-C7 $(285 \%)$. 
Another numerical study concluded that the disc is less important than the ligaments in resisting sagittal moments ( $\mathrm{Ng}$ and Teo 2001) which is what we observed for injuries at C4-C5 and C6-C7, but not at C2-C3. Their study was performed on the C4-C6 segment only. A FE study concluded that the absence of nucleus affected the model only at loads lower than $2 \mathrm{Nm}$ (Erbulut et al. 2014). However, our study proposed a rupture through the entire disc since AF rupture is more frequent than disc avulsion at the cervical spine (Crowell et al. 1993; Taylor and Twomey 1993). An experimental study performed an anterior incision into the C5-C6 IVD which had a statistically significant impact on flexion and extension ROM (Richter et al. 2000). However, they modeled their disco-ligamentous sequential resection from anterior to posterior.

A study reproducing unilateral facet injuries on C4-C5 and C6-C7 spinal segments demonstrated that both the nucleus and $\mathrm{AF}$ are important stabilizing structures at the cervical spine (Nadeau et al. 2012). However, their specimens only comprised one FSU. In our study, a difference was seen in local ROM at the injury between $1 / 3$ disc rupture and 2/3 disc rupture at $\mathrm{C} 2-\mathrm{C} 3$ and $\mathrm{C} 6-\mathrm{C} 7$, but not at $\mathrm{C} 4-\mathrm{C} 5$. Therefore, both the nucleus and AF are stabilizing structures in flexion, but to a different extent depending on the spinal level.

Vertebrae's centroid's position showed no rearrangement of the spinal curvature and no subluxation for injuries at C4-C5 and C6-C7 which could be explained by the pure flexion loading used. For injuries at C2-C3 however, the vertebrae position pattern in flexion varied depending on the IVD rupture state. The disc seems to have an 
important impact on the rotational axis of C2-C3. At two injury states (PLC rupture and complete disc rupture), $\mathrm{C} 2$ moved significantly more anteriorly than $\mathrm{C} 3$ in comparison to the baseline. This suggests a post-traumatic spinal cord impingement. At complete disc rupture, this high anterior displacement combined with high local rotation lead to an important change in the antero-posterior position of the $\mathrm{C} 2-\mathrm{C} 3$ facets. This could lead to luxation and compression of the spinal cord (McLoughlin et al. 2014). This phenomenon was observed for a non-traumatic flexion moment $(2 \mathrm{Nm})$ which shows the importance of post-traumatic immobilization in comparison. Since this happened at 51 degrees of $\mathrm{C} 2-\mathrm{T} 1$ flexion, it shows that the mobility permitted by cervical collars is not sufficiently restrictive: 40.8 degrees of maximal head flexion measured on voluntary subjects (Lebel et al. 2018) and 30 degrees of neck flexion measured on cadavers with a cervical instability (Horodyski et al. 2011).

Some limitations of this study should be listed. Flexion only was performed since the PLC is mostly solicited in flexion and current cervical collars do not restrict neck flexion efficiently. Furthermore, excessive flexion of an unstable spine could lead to subluxation and dislocation. However, having a complete overview of PLC and disc injuries effect on spinal stability would require studying all three anatomical planes. Also, loading was done in pure flexion which is a simplification of the multidirectional physiological loads present in the spine. The contact at the facet joints was simplified as a frictionless interface which could have facilitated the facet subluxation that was observed for injury at C2-C3. Future works could integrate a sensitivity analysis on the facets interface type. Muscles were not modeled while it has been shown that muscles activation can restrict movements with voluntary subjects (Eckner et al. 2014). Furthermore, gravity was not taken into account. The addition of a pre-load to represent 
the gravitational forces would pre-constrain the spine but would only minimally increase the mobility of the cervical spine in flexion (Barrey et al. 2015).

Disc rupture was simplified by creating a gap in the middle of the disc. The anterior $\mathrm{AF}$ is thicker than the lateral and posterior $\mathrm{AF}$ in the cervical spine (Tonetti et al. 2005). During traumatic flexion, the core and posterior AF are likely to be ruptured as the injury grows. The anterior AF is more firmly attached to the bone and tends to remain intact in flexion injuries which represents our $2 / 3$ rupture scenario. In cervical spine flexion injuries, disc rupture happens often between the disc and the endplate (Taylor and Twomey 1993; Tonetti et al. 2005). Here the rupture was modeled into the disc, but we assume that the spinal instability created is similar. Different models of disc rupture could be tested in a future analysis by varying the gap location. Future studies should investigate the effect of PLC and disc injuries on the spinal cord integrity to assess their potential functional impact. The impact of different cervical collar designs on spinal instability should also be studied. Personalization of the model to represent real-life traumatic cases from clinical data could also be performed.

To our knowledge, this study is the first to evaluate the effect of a posterior transversal disc rupture on stability. This FE analysis highlighted the importance of the PLC and IVD in stabilizing the cervical spine in flexion. The PLC is particularly important for spinal stability of the middle and lower cervical spine while the disc has more influence on the upper cervical spine. This study suggests that disco-ligamentous injuries should be handled with great care as sagittal motion may lead to cervical spinal instability. Trauma patients' manipulation and care should always be conducted with neck flexion kept to a minimum. Furthermore, pre-hospital cervical collars should be designed to restrict flexion of the cervical spine efficiently. 
Acknowledgements

This work was supported by the Canada research chair in biomechanics of head and spine injuries under Grant number 231815; the foundation J.A. DeSeve; and the Fonds de recherche du Quebec under Grant number 271503.

\section{Conflict of interest}

The authors declare that they have no conflict of interest. 


\section{References}

Ala'a OO, Smith K, Stoelwinder JU, Middleton J, Jennings PA. 2015. Should suspected cervical spinal cord injury be immobilised?: a systematic review. Injury. 46(4):528-535.

Blauth M, Mair G, Schmid R, Reinhold M, Rieger M. 2007. Classification of injuries of the subaxial cervical spine. AO Spine Manual: clinical applications. 2:21-38.

Barrey C, Rousseau M, Persohn S, Campana S, Perrin G, Skalli W. 2015. Relevance of using compressive preload in the cervical spine: an experimental and numerical simulating investigation. European Journal of Orthopaedic Surgery \& Traumatology. 25:155-165.

Crowell RR, Shea M, Edwards WT, Clothiaux PL, Hayes W. 1993. Cervical injuries under flexion and compression loading. Journal of spinal disorders. 6(2):175-181.

DeWit JA, Cronin DS. 2012. Cervical spine segment finite element model for traumatic injury prediction. Journal of the mechanical behavior of biomedical materials. 10:138150 .

Eckner JT, Oh YK, Joshi MS, Richardson JK, Ashton-Miller JA. 2014. Effect of neck muscle strength and anticipatory cervical muscle activation on the kinematic response of the head to impulsive loads. The American journal of sports medicine. 42(3):566576.

Engsberg JR, Standeven JW, Shurtleff TL, Eggars JL, Shafer JS, Naunheim RS. 2013. Cervical spine motion during extrication. The Journal of emergency medicine. 44(1):122-127.

Erbulut D, Zafarparandeh I, Lazoglu I, Ozer A. 2014. Application of an asymmetric finite element model of the C2-T1 cervical spine for evaluating the role of soft tissues in stability. Medical engineering \& physics. 36(7):915-921.

Fujimura Y, Nishi Y, Chiba K, Kobayashi K. 1995. Prognosis of neurological deficits associated with upper cervical spine injuries. Paraplegia. 33:195-202.

Goel VK, Clark CR, McGowan D, Goyal S. 1984. An in-vitro study of the kinematics of the normal, injured and stabilized cervical spine. Journal of biomechanics. 17(5):363-376.

Gore DR, Sepic SB, Gardner GM. 1986. Roentgenographic findings of the cervical spine in asymptomatic people. Spine. 11 (6):521-524.

Horodyski M, DiPaola CP, Conrad BP, Rechtine II GR. 2011. Cervical collars are insufficient for immobilizing an unstable cervical spine injury. The Journal of emergency medicine. 41(5):513-519.

Jubert P, Lonjon G, de Loubresse CG, Bone and Joint Trauma Study Group. 2013. Complications of upper cervical spine trauma in elderly subjects. A systematic review of the literature. Orthopaedics \& Traumatology: Surgery \& Research. 99(6):S301-S312. 
Kallemeyn N, Gandhi A, Kode S, Shivanna K, Smucker J, Grosland N. 2010. Validation of a C2-C7 cervical spine finite element model using specimen-specific flexibility data. Medical engineering \& physics. 32(5):482-489.

Kim JG, Bang SH, Kang GH, Jang YS, Kim W, Choi HY, Kim GM. 2018. Comparison of the efficacy of three cervical collars in restricting cervical range of motion: A randomized study. Hong Kong Journal of Emergency Medicine.:1024907918809499.

Lebel K, Chenel V, Boulay J, Boissy P. 2018. Quantitative Approach Based on Wearable Inertial Sensors to Assess and Identify Motion and Errors in Techniques Used during Training of Transfers of Simulated c-Spine-Injured Patients. Journal of healthcare engineering. 2018.

Mattucci SF, Cronin DS. 2015. A method to characterize average cervical spine ligament response based on raw data sets for implementation into injury biomechanics models. Journal of the mechanical behavior of biomedical materials. 41:251-260.

Mattucci SF, Moulton JA, Chandrashekar N, Cronin DS. 2012. Strain rate dependent properties of younger human cervical spine ligaments. Journal of the mechanical behavior of biomedical materials. 10:216-226.

McLoughlin LC, Jadaan M, McCabe J. 2014. Severe sprains of the sub-axial cervical spine in adolescents: a diagnostic and therapeutic challenge. European Spine Journal. 23(2):150-156.

Mustafy T, Moglo K, Adeeb S, El-Rich M. 2016. Injury mechanisms of the ligamentous cervical C2-C3 Functional Spinal Unit to complex loading modes: Finite Element study. Journal of the mechanical behavior of biomedical materials. 53:384-396.

Nadeau M, McLachlin SD, Bailey SI, Gurr KR, Dunning CE, Bailey CS. 2012. A biomechanical assessment of soft-tissue damage in the cervical spine following a unilateral facet injury. JBJS. 94(21):e156.

$\mathrm{Ng} \mathrm{H}-\mathrm{W}$, Teo E-C. 2001. Nonlinear finite-element analysis of the lower cervical spine (C4-C6) under axial loading. Clinical Spine Surgery. 14(3):201-210.

Nightingale RW, Chancey VC, Ottaviano D, Luck JF, Tran L, Prange M, Myers BS. 2007. Flexion and extension structural properties and strengths for male cervical spine segments. Journal of biomechanics. 40(3):535-542.

Nightingale RW, Winkelstein BA, Knaub KE, Richardson WJ, Luck JF, Myers BS. 2002. Comparative strengths and structural properties of the upper and lower cervical spine in flexion and extension. Journal of biomechanics. 35(6):725-732.

Panjabi M, White III A, Johnson R. 1975. Cervical spine mechanics as a function of transection of components. Journal of biomechanics. 8(5):327-336.

Park WM, Kim K, Kim YH. 2015. Changes in range of motion, intradiscal pressure, and facet joint force after intervertebral disc and facet joint degeneration in the cervical spine. Journal of Mechanical Science and Technology. 29(7):3031-3038. 
Pintar FA, Yoganandan N, Myers T, Elhagediab A, Sances Jr A. 1992. Biomechanical properties of human lumbar spine ligaments. Journal of biomechanics. 25(11):13511356.

Pitzen T, Lane C, Goertzen D, Dvorak M, Fisher C, Barbier D, Steudel W-I, Oxland T. 2003. Anterior cervical plate fixation: biomechanical effectiveness as a function of posterior element injury. Journal of Neurosurgery: Spine. 99(1):84-90.

Pospiech J, Stolke D, Wilke HJ, Claes LE. 1999. Intradiscal pressure recordings in the cervical spine. Neurosurgery. 44(2):379-384.

Przybylski GJ, Carlin GJ, Patel PR, Woo SL. 1996. Human anterior and posterior cervical longitudinal ligaments possess similar tensile properties. Journal of orthopaedic research. 14(6):1005-1008.

Rasoulinejad P, McLachlin SD, Bailey SI, Gurr KR, Bailey CS, Dunning CE. 2012. The importance of the posterior osteoligamentous complex to subaxial cervical spine stability in relation to a unilateral facet injury. The Spine Journal. 12(7):590-595.

Richter M, Wilke H-J, Kluger P, Claes L, Puhl W. 2000. Load-displacement properties of the normal and injured lower cervical spine in vitro. European Spine Journal. 9(2):104-108.

Schmidt H, Heuer F, Simon U, Kettler A, Rohlmann A, Claes L, Wilke H-J. 2006. Application of a new calibration method for a three-dimensional finite element model of a human lumbar annulus fibrosus. Clinical Biomechanics. 21(4):337-344.

Shirazi-Adl A, Ahmed A, Shrivastava S. 1986. A finite element study of a lumbar motion segment subjected to pure sagittal plane moments. Journal of biomechanics. 19(4):331-350.

Taso M, Fradet L, Callot V, Arnoux PJ. 2015. Anteroposterior compression of the spinal cord leading to cervical myelopathy: a finite element analysis. Computer Methods in Biomechanics and Biomedical Engineering. 18(sup1):2070-2071. doi:10.1080/10255842.2015.1069625.

Taylor J, Twomey L. 1993. Acute injuries to cervical joints. An autopsy study of neck sprain. Spine. 18(9):1115-1122.

Tonetti J, Potton L, Riboud R, Peoc'h M, Passagia J-G, Chirossel J-P. 2005.

Morphological cervical disc analysis applied to traumatic and degenerative lesions. Surgical and Radiologic Anatomy. 27(3):192-200.

Vaccaro A, Hulbert R, Patel A, Fisher C, Dvorak M, Lehman R, Anderson P, Harrop J, Oner F, Arnold P. 2007. The subaxial cervical spine injury classification system: a novel approach to recognize the importance of morphology, neurology, and integrity of the disco-ligamentous complex. Spine. 32:2365-2374.

Wagnac E, Arnoux P-J, Garo A, Aubin C-E. 2012. Finite element analysis of the influence of loading rate on a model of the full lumbar spine under dynamic loading conditions. Medical \& biological engineering \& computing. 50(9):903-915. 
Wheeldon JA, Pintar FA, Knowles S, Yoganandan N. 2006. Experimental flexion/extension data corridors for validation of finite element models of the young, normal cervical spine. Journal of biomechanics. 39(2):375-380.

White A, Johnson R, Panjabi M, Southwick W. 1975. Biomechanical analysis of clinical stability in the cervical spine. Clinical orthopaedics and related research.(109):85-96.

White A, Panjabi M. 1990. Clinical biomechanics of the spine. 2nd ed. Philadelphia: J. B. Lippincott Company. 
Table 1. Material Properties of Intervertebral Disc (Moonley-Rivlin Model)

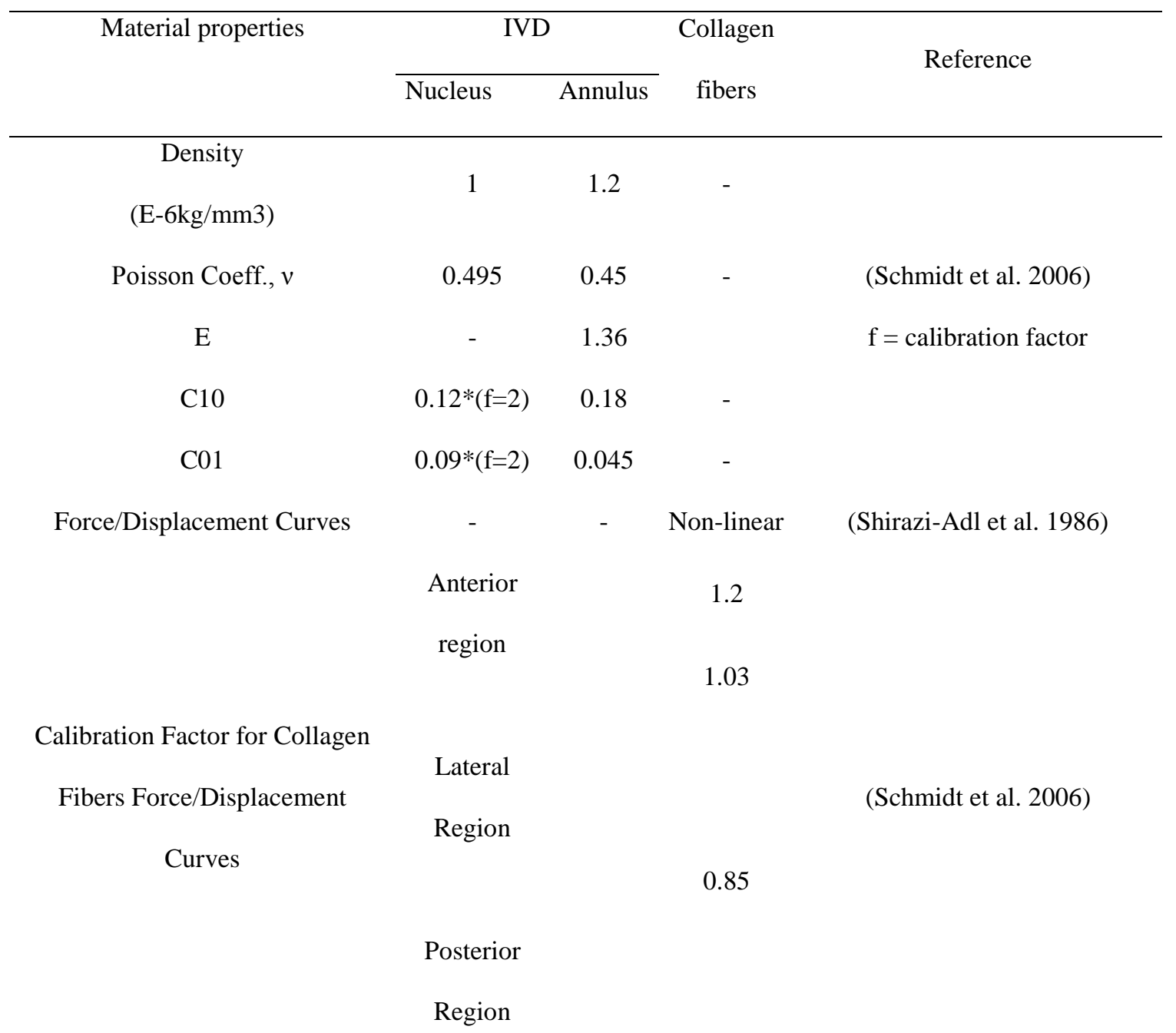


Figure 1. Finite element model of the cervical spine: a) complete C2-T1 model and b) C5 vertebra with ligaments and intervertebral disc

Figure 2. Sagittal cross-section of the finite element model of the IVD posterior rupture at C6-C7: a) one third rupture, b) two thirds rupture and c) complete rupture

Figure 3. Comparison of function spinal units response under flexion (positive) and extension (negative) of C2-T1 cervical segment with in vitro studies

Figure 4. Comparison of C2-T1 segment response under flexion (positive) and extension (negative) of C2-T1 cervical segment with in vitro studies

Figure 5. Intradiscal pressure in flexion at $\mathrm{C} 3-\mathrm{C} 4$ and at $\mathrm{C} 5-\mathrm{C} 6$ compared to in vitro data

Figure 6. Evolution of the functional spinal units range of motion at each injury level Figure 7. Centroids position $(\mathrm{mm})$ in flexion in the sagittal plane at all vertebral levels with and without PLC and IVD injury

Figure 8. C2 and C3 at $2 \mathrm{Nm}$ flexion: a) in non-traumatic (baseline) model and b) following PLC and complete disc rupture 